\title{
(IN)JUSTIÇA GLOBAL, (PÓS)(DE)COLONIALIDADE E JUÍZES TRANSFRONTEIRIÇOS
}

http://dx.doi.org/10.21527/2176-6622.2019.52.37-50

Recebido em: 1이/2019

Modificações requeridas em: 22/7/2019

Aceito em: 18/8/2019

\section{Cristiano Becker Isaia}

Doutor e pós-doutor em Direito pela Universidade do Vale do Rio dos Sinos. Professor-adjunto lotado no Programa de Pós-Graduação em Direito e no Departamento de Direito da Universidade Federal de Santa Maria. Professor-adjunto do curso de Direito da Universidade Franciscana. Professor da Antonio Meneghetti Faculdade. Coordenador do Núcleo de Estudos Avançados em Processo Civil da Universidade Federal de Santa Maria (www.ufsm.br/neapro). Autor das obras Processo civil, atuação judicial e hermenêutica filosófica (2011), Processo civil e hermenêutica: a crise do procedimento ordinário e o redesenhar da jurisdição processual civil pela sentença liminar de mérito (2012) e Processo civil e hermenêutica: os fundamentos do novo CPC e a necessidade de se falar numa filosofia do processo (2017). Advogado. http://lattes.cnpq.br/1677439477708820 cbisaia@gmail.com

Andreia Momolli

Mestranda no Programa de Pós-Graduação em Direito da Universidade Federal de Santa Maria. Juíza Federal Substituta, lotada na 1a Vara Federal de Santa Maria. http://lattes.cnpq.br/7350660047372303. andreiamomolli@hotmail.com

\section{RESUMO}

O presente artigo investiga as condições de possibilidade de o comércio transfronteiriço entre juízes ser fator de (pós)(de)colonialidade, promovendo justiça globalmente. Trata da (in)justiça global, a partir da explicitação das teorias de justiça de Rawls, o primeiro a tentar conciliar liberdade e igualdade e considerar o além-fronteiras dos Estados, e de Sen, crítico de Rawls quanto à concepção ideal de justiça, focado na promoção das liberdades reais. Relaciona-as aos estudos de Filosofia contemporânea acerca das injustiças globais, especificamente, de Pogge no que se refere à injustiça socioeconômica, de Honneth, Jouannet e Benhabib quanto à opressão da diversidade cultural e de identidade, e de Jouannet, Pahuja, Lorca, Dussel e Silva Santos no que tange à subalternização dos saberes e práticas político-jurídicas. Estuda a (pós)(de) colonialidade, revelando a tradução da colonialidade política em epistêmica, expondo as teorias pós-coloniais e decoloniais que pretendem esclarecer e minimizar o impacto da lógica colonial na produção do conhecimento, inclusive na construção do Direito. A partir disso, alerta para os riscos de o comércio transfronteiriço entre juízes, intercâmbios não vinculantes entre magistrados de diferentes Estados mobilizados por uma consciência crescente de um patrimônio democrático comum, perpetuar a lógica colonial. Incentiva que os juízes transfronteiriços realizem o comércio de decisões na condição instrumento de emancipação das populações das ex-colônias e de convivência cultural, dada a profundidade de fundamentação em temas de maior incidência no sul global e a indispensabilidade dos saberes locais para promoção da paz. O método de abordagem foi o dedutivo. O procedimento adotado foi de pesquisa bibliográfica.

Palavras-chave: Injustiças globais. Colonialidade. Comércio de decisões.

\section{GLOBAL (IN)JUSTICE, (POST) (DE) COLONIALITY AND JUDGES CROSS-BORDER}

\section{ABSTRACT}

The article investigates the conditions for the possibility of cross-border trade between judges to be a factor of (post) (de) coloniality, promoting justice globally. It deals with global (in) justice, starting from the explanation of Rawls's theory of justice, the first to attempt to reconcile liberty and equality and to consider the cross-border of states, and of Sen's theory of justice, a critic of Rawls's ideal conception of justice, focused on promoting real freedoms. It relates them to studies of contemporary philosophy about global injustices, specifically Pogge's regarding socioeconomic injustice, Honneth, Jouannet and Benhabib's oppression of cultural diversity and identity, and Jouannet's, Pahuja and Lorca's regarding the subordination of political-legal knowledge and practices. It studies (post) (de) coloniality, revealing the translation of political coloniality into epistemic, exposing postcolonial and decolonial theories that seek to clarify and minimize the impact of colonial logic on knowledge production, including the construction of Law. From this it warns of the risks that cross-border trade between judges, non-binding exchanges between magistrates of different states mobilized by a growing awareness of a common democratic heritage, will perpetuate the colonial logic. It encourages cross-border judges to trade in judgments as an instrument of emancipation of the populations of former colonies and of cultural coexistence, given the depth of grounding in issues of greater incidence in the Global South and the indispensability of local knowledge for the promotion of peace. The approach method was the deductive one. The procedure adopted was bibliographic research.

Keywords: Global injustices. Coloniality. Trade of decisions.

\section{SUMÁRIO}

1 Introdução. 2 (In)Justiça Global. 3 (Pós)(De)Colonialidade. 4 (Pós)(De)Colonialidade e o Comércio entre Juízes Transfronteiriços. 5 Conclusão. 6 Referências. 


\section{INTRODUÇÃO}

As teorias liberais de Justiça Global desenvolvidas por Rawls, que inaugurou as tentativas de conciliação dos valores igualdade e liberdade (SANDEL, 2015), e Sen, que refutou o institucionalismo transcendental e pretendeu formular uma teoria da justiça atenta à vida que as pessoas podem viver de fato (SEN, 2011) são referências àqueles que pretendem investigar contemporaneamente a respeito das formas de (in)justiça global, quais sejam, desigualdade econômica, opressão da diversidade cultural e de identidade e subalternização dos saberes e práticas político-jurídicas (ANTONETTE; POZZATTI JUNIOR, 2018).

A injustiça socioeconômica é o tema de Pogge, que ampliou o pensamento de Rawls, propondo uma abordagem institucional no sentido global para interno (ANTONETTE; POZZATTI JUNIOR, 2018). O Direito Internacional do Desenvolvimento também refere-se às desigualdades econômicas e culminou na criação do Índice de Desenvolvimento Humano - o qual teve a colaboração de $\operatorname{Sen}^{1}$ - como contraponto ao desenvolvimento economicista. A opressão da diversidade cultural e de identidade é estudada por Jouannet, que cunhou a expressão Direito Internacional do Reconhecimento, em 2012, propondo práticas, discursos e normas jurídicas baseadas no respeito do direito do outro (ANTONETTE; POZZATTI JUNIOR, 2018), por Honneth que, a partir das categorias de reconhecimento elencadas por Hegel, procurou apresentar uma justificação normativa para a positivação de pautas identitárias (HONNETH, 2003 ) e por Benhabib, que é quem dá ao direito dos outros uma dimensão jurídica cosmopolita (BENHABIB, 2004).

A subalternização dos saberes e práticas político-jurídicas diz respeito especialmente às práticas que perpetuam a colonialidade, ${ }^{2}$ expressa inicialmente como política, exercida pela presença dos Estados europeus nas colônias, mas que se revela sobretudo epistêmica, marcando diferenças e produzindo conceitos binários como barbárie e civilização, tradição e modernidade, pobreza e desenvolvimento, entre outros, resultando num produto ideológico construído do dispositivo de poder moderno/colonial, submetendo as populações que estão fora do centro global à universalidade ocidental (CASTRO-GÓMEZ, 2005). São as teorias como as de Jouannet, as pós-coloniais na linha de Pahuja, e decoloniais, explicitadas por Lorca, Dussel e Sousa Santos, que desvelam e combatem a perpetuidade da subordinação colonial na produção do conhecimento.

Nesse contexto insere-se a construção do Direito e a intensificação dos intercâmbios entre os juízes para além das fronteiras políticas, o que é nominado de comércio de decisões por Allard e Garapon (2005), emerge como zona propícia a essa dominação, mas também pode servir de efetivo instrumento de emancipação das populações do sul global, dando voz à diversidade. Esta é a problemática que se pretende enfrentar nessa pesquisa, qual seja, a respeito das condições de possibilidade de o comércio de decisões entre juízes transfronteiriços ser fator de (pós)(de)colonialidade, promovendo justiça globalmente. Para tanto, é feita uma divisão em três seções: a primeira estuda a (in)justiça global, seguida do referente especificamente à (pós)(de) colonialidade e a terceira trata da (pós)(de)colonialidade e o comércio entre juízes transfronteiriços. $O$ método utilizado foi o dedutivo e o procedimento de pesquisa bibliográfica.

\section{2 (IN)JUSTIÇA GLOBAL}

Rawls inaugurou uma nova perspectiva para a filosofia política e para a Justiça, ainda que fortemente influenciado pelos autores do século 19 (raciocina a partir de um contrato social, como Locke e Rousseau), preocupando-se em desenvolver uma teoria da Justiça que considerasse o além-fronteiras dos Estados e que fosse igualmente respeitosa com os dois maiores valores morais, quais sejam, liberdade e igualdade (SANDEL, 2015), que até então eram considerados contraditórios e inconciliáveis. Para o jusfilósofo, a liberdade é o valor supremo da vida humana, no que se aproxima de Kant, compreendendo-a como valor fundamental de convi-

\footnotetext{
Nesse sentido, informa o Programa das Nações Unidas para o Desenvolvimento, disponível em http://www.br.undp.org/content/brazil/ pt/h ome/idho/conceitos/o-que-e-o-idh.html. Acesso em: 26 jul. 2019.

2 Mignolo explica que foi o sociólogo peruano Anibal Quijano, no final dos anos 80 e início dos anos 90 quem introduziu o conceito de colonialidade, nomeando a lógica subjacente da fundação e do desdobramento da civilização ocidental desde o Renascimento, tendo os colonialismos históricos uma dimensão constituinte, embora minimizada (MIGNOLO, 2017).
} 
vência entre os membros de uma comunidade política. Isso lhe garantiu o status de pensador liberal. Considera Rawls, entretanto, que a potencialização da liberdade ocorre com a sua limitação, o que exige razoabilidade, que é a capacidade de desenvolver o senso de justiça, ou seja, o critério de reciprocidade (igualdade).

Nesse sentido, no pensamento de Rawls, por exemplo, nem mesmo o livre-mercado operando em sociedade com oportunidades idênticas de educação conseguirá atingir uma justa distribuição de renda e riqueza, tendo em vista a arbitrariedade na distribuição dos bens naturais. A loteria natural é, tanto quanto a fortuna histórica e social, causa de injustiça, devendo ser buscada uma concepção equânime. Pelo princípio da diferença, aqueles mais favorecidos pela natureza só devem usufruir de sua boa sorte de maneira a melhorar a posição dos menos favorecidos, devendo as contingências trabalhar para o bem dos menos afortunados (SANDEL, 2015).

\begin{abstract}
Digamos agora que uma sociedade é bem-ordenada não apenas quando está planejada para promover o bem de seus membros mas quando é também efetivamente regulada por uma concepção pública de justiça. Isto é, trata-se de uma sociedade na qual (1) todos aceitam e sabem que os outros aceitam os mesmos princípios de justiça, e (2) as instituições sociais básicas geralmente satisfazem, e geralmente se sabe que satisfazem, esses princípios. Nesse caso, embora os homens possam fazer excessivas exigências mútuas, eles contudo reconhecem um ponto de vista comum a partir do qual suas reivindicações podem ser julgadas. Se a inclinação dos homens ao interesse próprio torna necessária a vigilância de uns sobre os outros, seu sentido público de justiça torna possível a associação segura (RAWLS, 2000, p. 5).
\end{abstract}

Ao construir sua teoria de Justiça como equidade, pretendeu Rawls estabelecer os critérios de justa distribuição de bens, num ambiente de escassez moderada de recursos, inclusive considerando as diferenças espaciais (entre as pessoas ao redor do mundo) e temporais (justiça intergeracional). Atribuiu às instituições a tarefa de alcançar a sociedade justa, considerando a justiça distributiva uma função do Estado em relação às pessoas. Superando a concepção política clássica, de acordo com a qual se estabelecia o que as pessoas tinham de fazer para instituí-la, percebeu Rawls o pluralismo como decorrência da ideia de liberdade, em que pessoas diferentes, mediante a razão, têm variadas concepções de bens, cada vez mais dessemelhantes, sendo a tarefa da política não mais a disseminação de um modo excelente de vida, mas a conservação dos direitos naturais (liberdade) (SEN, 2011).

O jusfilósofo propôs uma nova forma de contrato social que parte da ideia de posição original, na qual os participantes decidem os princípios necessários para a convivência sob o "véu da ignorância". Trata-se de um modelo hipotético, e não histórico, em que os indivíduos não conhecem sua posição na vida real (virtude da imparcialidade). A partir disso, Rawls estabelece como bens primários direitos e liberdades básicas, oportunidades, renda, fortuna e bases sociais do autorrespeito. No véu da ignorância, a estrutura básica da sociedade tutela as vulnerabilidades, garantindo-se o máximo para cada um, desde que se consiga se fornecer o máximo a quem está na pior posição (SEN, 2011).

Analisemos agora uma experiência mental: suponhamos que, ao nos reunir para definir os princípios, não saibamos a qual categoria pertencemos na sociedade. Imaginemo-nos cobertos por um "véu de ignorância" que temporariamente nos impeça de saber quem realmente somos. Não sabemos a que classe social ou gênero pertencemos e desconhecemos nossa raça ou etnia, nossas opiniões políticas ou crenças religiosas. Tampouco conhecemos nossas vantagens ou desvantagens - se somos saudáveis ou frágeis, se temos alto grau de escolaridade ou se abandonamos a escola, se nascemos em uma família estruturada ou em uma família desestruturada. Se não possuíssemos essas informações, poderíamos realmente fazer uma escolha a partir de uma posição original de equidade. Já que ninguém estaria em uma posição superior de barganha, os princípios escolhidos seriam justos. É assim que Rawls entende um contrato social - um acordo hipotético em uma posição original de equidade. Rawls nos convida a raciocinar sobre os princípios que nós - como pessoas racionais e com interesses próprios - escolheríamos caso estivéssemos nessa posição. Ele não parte do pressuposto de que todos sejamos motivados apenas pelo interesse próprio na vida real; pede somente que deixemos de lado nossas convicções morais e religiosas para realizar essa experiência imaginária. Que princípios escolheríamos? (SANDEL, 2015, p. 140).

Rawls desenvolveu uma concepção política de justiça, porque enxergou na limitação da liberdade através das instituições o instrumento de sua maximização. Deve existir instituições para equalizar as diferenças que provêm das liberdades. Estabeleceu, assim, dois princípios de justiça, o princípio da liberdade, que impõe 
o máximo de liberdade possível que possa garantir liberdade para todos, e o princípio da igualdade, de forma que as desigualdades têm de ser distribuídas de forma a garantir os maiores benefícios aos menos favorecidos e que o mérito só tem sentido num ambiente com igualdade de oportunidades, o que também diz respeito às relações entre os Estados. A autodeterminação dos povos significa que a liberdade pode ser pensada para as pessoas físicas e para as pessoas morais. A igualdade entre os Estados está ligada à ideia de que as práticas das diversas comunidades discursivas é um desafio para o instrumento criado para a convivência, com o Direito Internacional sendo uma das instituições que a assegura.

Críticas construtivas a Rawls foram realizadas por Amartya Sen (2011), relacionadas à concepção ideal de Justiça. A proposta é de que a maximização da experiência ocorra a partir do que pode ser instituído. Ambos os teóricos dependem da argumentação racional e fazem apelo às exigências do debate público, mas o indiano pensa a justiça de um ato não pela correspondência com o ideal, mas pela capacidade de promoção das liberdades reais. Sen faz uma crítica a todo o institucionalismo de Rawls, afirmando que só se tem liberdade se houver capacidade de fazer escolhas, e que os direitos não devem prevalecer sobre o atendimento das necessidades concretas das pessoas.

Apresento aqui uma teoria da justiça em um sentido bem amplo. $O$ objetivo é esclarecer como podemos proceder para enfrentar questões sobre a melhoria da justiça e a remoção da injustiça, em vez de oferecer soluções para questões sobre a natureza da justiça perfeita. Isso se diferencia claramente das teorias da justiça predominantes na filosofia moral e política contemporânea (SEN, 2011, p. 11).

Sen questiona a métrica dos bens primários, que diz dever considerar outras variáveis, relacionadas à capacidade de conversão dos bens primários em bem viver, e a factibilidade de um acordo transcendental, ao afirmar que é possível que não se chegue a um acordo do que sejam as instituições justas ainda que se esteja submetido ao véu da ignorância, isso porque as ideias de Justiça variam conforme as sociedades em que elas estão de fato inseridas. Para Sen, ainda, não há sentido em se identificar a situação perfeita e inacessível, e propõe um ranking de alternativas viáveis. $O$ indiano faz uma crítica à negligência global, afirmando que a abordagem rawlsiana está presa ao Estado-nação, possuindo limitações ao enfrentamento de questões de justiça global que independam da atuação estatal (SEN, 2011).

Sen propõe uma teoria da Justiça pautada na abordagem das capacidades focada nas realizações, sem negligenciar a importância das instituições, mas com ênfase na vida que as pessoas podem viver de fato. Adere à teoria da escolha social (diferente da escolha racional), sustentando uma tese universalista (cosmopolita) e não comunitarista (lealdade para com quem pertence à mesma comunidade). Funda-se na corrente iluminista comparativista, não contratualista, e tem como metodologia as comparações focadas nas realizações sociais, com interesse na remoção de injustiças evidentes do mundo em que se vive. A injustiça, dessa forma, pode estar conectada à transgressão de comportamento, ao modo como se vive, e não ao funcionamento das instituições, responsabilizando todos pela vida que os outros levam, em múltiplos graus (SEN, 2011).

O jusfilósofo diz ser irresponsável o individualismo contemporâneo e considera a atividade cooperativa das pessoas ao afirmar que a motivação vai além dos benefícios mútuos. Propõe a ideia do espectador imparcial em contraponto ao véu da ignorância: enquanto este tem o viés do autointeresse, aquele pressupõe a alteridade. A teoria da escolha social por ele defendida afirma que existem ganhos que não são diretos, decorrentes de se fazer parte da coletividade. Ao satisfazer às necessidades dos demais, não quer dizer que não estarei satisfazendo as minhas. Ainda, para Sen, o ato justo é aquele que promove capacidades para que as pessoas possam eventualmente fazer opções. A vida boa é medida pela efetiva liberdade das pessoas e a necessidade dos bens primários se dá conforme nossas características concretas (sujeito, e não indivíduo) (SEN, 2011).

Sen é um cosmopolita, que entende que as ideias de Justiça devem se espalhar para todo o globo, argumentando pela possibilidade de uma justiça global, baseada na racionalidade global, que resguarde os direitos humanos, não fundada no estatocentrismo rawlsiano. Para o teórico, a promoção da Justiça global independe de uma entidade supranacional, mas está vinculada ao debate entre os sujeitos que compõem o cenário internacional. É um problema local, pois ligada ao desenvolvimento das capacidades locais, ainda que reconheça o papel relevante das instituições internacionais na promoção das capacidades (SEN, 2011). 
Rawls, o primeiro a tentar conciliar liberdade e igualdade e considerar o além-fronteiras dos Estados, e Sen, focado na promoção das capacidades, naquilo que as pessoas podem realizar efetivamente, são referências àqueles que pretendem investigar contemporaneamente a respeito das formas de (in)justiça global, as quais podem ser elencadas como desigualdade econômica, opressão da diversidade cultural e de identidade e subalternização dos saberes e práticas político-jurídicas (ANTONETTE; POZZATTI JUNIOR, 2018).

A injustiça socioeconômica é o tema de Pogge, que ampliou o pensamento de Rawls, propondo uma abordagem institucional no sentido global para interno (ANTONETTE; POZZATTI JUNIOR, 2018). Para o autor, há uma conexão necessária em nível doméstico, internacional e global e a facilidade dos fluxos, comércio e produção circularizados, responsáveis pela erosão da soberania e pela interdependência global, ensejaram a alocação de poder e de valor em centros específicos de produção de saber/poder, à custa da periferia. Pogge preocupa-se com o universalismo moral, com a distribuição de bens e riquezas, com o papel das instituições e regras na Justiça global (POGGE, 2007).

A pobreza superou a guerra como a maior causa de miséria humana evitável. Pogge afirma que acabar com a fome é possível, mas falta vontade política. Diz que há um contexto de prosperidade global sem precedentes, que permitiria acaba com a pobreza alocando apenas $1 \%$ dos ingressos dos países ricos, mas que a desigualdade entre pobres e ricos continua a crescer. Para o jusfilósofo, as condições de vida em qualquer local da Terra são profundamente afetadas por interações internacionais. Assim, propõe um design alternativo das regras supranacionais, que permitisse aos pobres uma participação proporcional no crescimento econômico global, e reforma das regras da economia mundial, de modo a não violar os direitos humanos, bem como a responsabilização dos cidadãos que apoiam ou toleram políticas injustas de seus governos em relação a não compatriotas (POGGE, 2007).

Os dados essenciais sobre a vida e a morte das pessoas pobres do mundo são, afinal, indiscutíveis. Em vista da considerável interdependência global, é extremamente improvável que sua pobreza se deva apenas aos fatores locais e que nenhuma reforma factível da ordem mundial pudesse influir sobre a pobreza ou sobre esses fatores locais. Não menos inacreditável é a opinião de que a nossa é a melhor de todas as ordens mundiais possíveis, de que qualquer modificação dela só poderia agravar a pobreza. Então, devemos trabalhar juntos em todas as disciplinas a fim de conceber uma solução abrangente para o problema da pobreza global, e, acima das fronteiras, para a implementação política dessa solução (POGGE, 2007, p. 162).

A desigualdade social, entretanto, não é objeto de estudos apenas de Pogge. No pós-Segunda Guerra houve uma tentativa de estreitamento do fosso socioeconômico por meio da promoção e medição do desenvolvimento nos países pobres, a fim de possibilitar a todos o desfrute do bem-estar social. Foi feita a divisão entre nações desenvolvidas e subdesenvolvidas e o encorajamento destas à adoção do modelo desenvolvimentista, que se revelou uma continuidade da política de dominação colonial, por outros meios (JOUANNET, 2014). Foram criadas estruturas do comércio internacional que consolidaram interesses dos atores centrais (Gatt). Já nos anos 70, entretanto, os países não alinhados organizaram-se para questionar esse modelo de desenvolvimento, a fim de buscar a justiça social do Terceiro Mundo. A ONU, inclusive, criou um programa específico de ação relacionado à Nova Ordem Econômica Internacional (Noei) (JOUANNET, 2014). Foi o surgimento do Direito do Desenvolvimento, inicialmente majoritariamente relacionado à economia, todavia.

Como resposta e diante da crise dos anos 80 , foi estabelecido o modelo neoliberal de desenvolvimento, que, no contexto de globalização econômica, configurou-se como ultraliberalismo e levou o poder político aos atores privados e a primazia das finanças sobre a economia e da economia sobre as demandas sociais (JOUANNET, 2014). Um novo Direito do Desenvolvimento, então, foi formulado, mais complexo e diversificado, com perspectiva não exclusivamente econométrica. Procurou colocar as pessoas no centro do desenvolvimento e preocupou-se em combater a desigualdade. O desenvolvimento sustentável é, assim, um contraponto ao desenvolvimento economicista, de forma a reestruturar o modelo de desenvolvimento econômico liberal numa abordagem de natureza multidimensional, preocupada com o meio ambiente, com as diferenças entre riqueza e pobreza e com a satisfação das necessidades do presente sem comprometer a capacidade das gerações futuras de satisfazer as próprias necessidades. 


\section{Debate}

Em 1992, a ONU considera, assim, ter desencadeado pela primeira vez em nível mundial uma visão renovada e comum do desenvolvimento, em particular com a Agenda 21, adotada naquele ano na cidade do Rio de Janeiro. Essa nova visão reflete uma compreensão multidimensional do desenvolvimento ignorada até então e, num nível ainda mais profundo, uma nova forma de ver e de preservar o futuro da humanidade, ao revisar nossos modos de vida, de produção e de consumo. O novo modelo de desenvolvimento opõe-se ao reducionismo economicista instigado pela globalização ultraliberal. Ele vai muito além do modelo clássico de desenvolvimento, englobando todo um conjunto de práticas e de princípios a serviço de novas finalidades (humana, social e ambiental), ao mesmo tempo em que prima por uma visão global, abrangendo tanto o Norte quanto o Sul, que ele não tinha antes (JOUANNET, 2014, p. 44).

Também foram construídas as noções de desenvolvimento humano e desenvolvimento social. A primeira relaciona-se à criação do Índice de Desenvolvimento Humano (IDH) para medição da riqueza dos países, ao lado do Produto Interno Bruto (PIB), métrica com foco exclusivamente econométrico. O IDH relaciona-se à capacidade do indivíduo e de suas escolhas e inclui análise de renda, educação e saúde. Pretende um desenvolvimento a serviço das pessoas e não dos Estados. Sua origem deu-se no âmbito do Programa das Nações Unidas para o Desenvolvimento, criação de Mahbub ul Haq em 1990, com a colaboração de Sem. ${ }^{3}$ No que se refere ao desenvolvimento social, diz respeito ao encorajamento dos Estados a distribuir equitativamente a riqueza e diminuir as desigualdades sociais e desemprego. É igualmente focado no indivíduo, e não no Estado, para superar a visão apenas econômica do desenvolvimento, e indica a necessidade de justiça social, de redução de pobreza, de criação de emprego. Questiona a relação entre expectativa de vida e renda, a fim de propor um novo olhar sobre uma boa vida (JOUANNET, 2014).

O estudo acerca da desigualdade econômica e de seus desdobramentos não exclusivamente economicistas é um dos focos da filosofia política contemporânea, conforme exposto (Pogge, Sen). Há, contudo, preocupação também com outras duas formas de injustiça globais, nominadas de opressão da diversidade cultural e de identidade e subalternização dos saberes e práticas político-jurídicas. Isso porque a instituição da liberdade e da igualdade não se relaciona exclusivamente à pobreza/riqueza, mas também ao reconhecimento das identidades/diferenças e à reprodução acrítica das teorias e práticas que provêm das estruturas de poder projetadas a partir da matriz colonial.

O Direito do Reconhecimento é uma resposta às injustiças globais de opressão das identidades e da diversidade cultural e tem relação com o aprimoramento da experiência de estar vivo. A expressão foi criada por Emmanuelle Tourme-Jouannet para se referir a uma nova demanda por Justiça internacional que engloba práticas, discursos e normas jurídicas baseadas no respeito ao direito do outro (ANTONETTE; POZZATTI JUNIOR, 2018, p. 134). Há vida para além do valor biológico, pelo que, para Hegel, o contrato social serve não para autopreservação, mas para o reconhecimento da individualidade. Honneth reinterpreta as categorias de reconhecimento elencadas por Hegel (amor, direito e solidariedade) a partir de uma perspectiva liberal, de forma a promover a autonomia, apresentando uma justificação normativa para a positivação das pautas identitárias. Afirma que a vida bem vivida depende da validação do outro (HONNETH, 2003).

Por isso, antes de toda explanação relativa ao conteúdo, é preciso clarificar primeiramente o status metodológico que reivindica uma teoria normativa que deve descrever o ponto final hipotético de uma ampliação das relações de reconhecimento; parece-me correto falar aqui de uma concepção formal de vida boa ou, mais precisamente, de eticidade. Só essa justificação metodológica permite, num segundo passo, retomar mais uma vez as intenções de Hegel e Mead, a fim de traçar a idéia de uma relação de reconhecimento pós-tradicional; o conceito desta tem de conter todos os pressupostos intersubjetivos que hoje precisam estar preenchidos para que os sujeitos se possam saber protegidos nas condições de sua auto-realização (HONNETH, 2003, p. 269-270).

Sobre o tema, leciona também Jouannet que a sociedade decente impõe valor jurídico ao reconhecimento, definindo identidades (voltado especialmente aos indivíduos), e isso tem razão diante da visualização da mazela de grupos estigmatizados e da indispensabilidade de reparação de erros históricos, o que implica processos diferentes em cada Estado. Já não apenas Estados são sujeitos de Direito Internacional, mas

\footnotetext{
3 Nesse sentido, consta informação no site do PNUD Brasil. Disponível em: http://www.br.undp.org/content/brazil/pt/home/idh0. html. Acesso em: 29 jul. 2019.
} 
também indivíduos e grupos. A padronização é uma herança eurocêntrica e motivo de subdesenvolvimento, ressalvando-se como limite à salvaguarda das práticas culturais os direitos humanos. Há necessidade de um novo paradigma, com reconhecimento da diferença em si, e não mais apenas da igualdade, que, na concepção formal, apenas favorece as maiorias (JOUANNET, 2012).

É, entretanto, Benhabib quem dá ao direito do reconhecimento uma dimensão jurídica cosmopolita, voltando-se ao estudo do direito dos outros (estrangeiros, refugiados, imigrantes, asilados, refugiados). Expõe a tensão entre normas de direitos humanos e a proteção das fronteiras e propõe reflexão sobre como unir a universalidade da ética com o particularismo do Direito. Para a professora, o sistema do Estado-nação regulou o pertencimento a partir de uma só categoria, qual seja, a cidadania, mas, diante da crise da territorialidade, que já não comporta mais as aspirações de identidade, faz-se necessário um ajuste da legitimidade democrática, em que se pense a soberania não como categoria do Estado, mas da população. A solução viria da iteração democrática: devem existir diversas instâncias de pertencimento político e não somente a estatal, formando um federalismo cosmopolita.

A intuição de que pode haver um elo crucial entre o tamanho do território e a forma de governo é antiga na história do pensamento político ocidental, e eu a aceito. Ao contrário de comunitaristas e nacionalistas liberais, entretanto, que vêem essa ligação principalmente baseada em laços culturais de identidade, preocupo-me com a lógica da representação democrática, que exige o fechamento para manter a legitimidade. Certamente, a identificação e a solidariedade não são de importância, mas devem ser considerados os ditames democráticos e as normas constitucionais. No espírito de Kant, portanto, defendi o universalismo moral e o federalismo cosmopolita. Eu não defendi abertura, mas bordas porosas; eu implorei pelos direitos de primeira entrada a refugiados e postulantes de asilo, mas aceito regulação democrática da primeira admissão para adesão plena; eu também argumentei por sujeitar leis que regem a naturalização a normas de direitos humanos e rejeitei a reivindicação de soberania para não permitir naturalização e barrar eventual cidadania de estrangeiros em seu meio (BENHABIB, 2004, p. 219-220, em livre tradução). ${ }^{4}$

A subalternização dos saberes e práticas político-jurídicas é a injustiça global relacionada à lógica da perpetuação da colonialidade, que iniciou do ser e se revelou epistêmica (CASTRO-GÓMEZ, 2005). Pressupõe a inferiorização, o pensamento binário hierarquizante próprio do racionalismo, que estigmatizou o outro (aquele que não tem o mesmo valor que eu). O excluído é o que não é. As grandes navegações inauguraram a modernidade, e com ela o domínio da razão e o centralismo do homem, e a colonialidade, desenvolvida como poder da administração colonial, usurpação, exploração. É o que melhor se explicitará na próxima seção, por meio dos estudos de Jouannet, de Pahuja (pós-coloniais) e de Lorca, Dussel e Souza Santos (decoloniais), que desvelam e pretendem minimizar a perpetuidade da subordinação colonial na produção do conhecimento.

\section{3 (PÓS)(DE)COLONIALIDADE}

Jouannet explica que o Direito dos povos modernos foi usado para justificar a dominação dos europeus sobre as partes do mundo que foram sendo gradualmente descobertas, o que foi favorecido pelo clima intelectual existente favorável às colonizações, pelas práticas econômicas e jurídicas alicerçadas nos ideais liberais do lluminismo e pelo racismo latente que acompanhava o movimento, que reforçou o estabelecimento da "superioridade natural" do homem branco europeu (de se observar que o termo "bárbaro" já existia no século 16 para designar o vizinho europeu, e não os selvagens americanos). Seu surgimento, entretanto, teria sido focado inicialmente para disciplinar a conduta dos Estados europeus e elevar a liberdade decorrente da soberania contra as tentativas de hegemonia das grandes potências europeias da época (JOUANNET, 2014).

\footnotetext{
${ }^{4}$ No original: The intuition that there may be a crucial link between territorial size and form of government is old in the history of western political thought, and it is one that I accept. Unlike communitarians and liberal nationalists, however, who view this link primarily as being based upon a cultural bond of identity, I am concerned with the logic of democratic representation, which requires closure for the sake of maintaining democratic legitimacy. Certainly, identification and solidarity are not unimportant, but they need to be leavened through democratic attachments and constitutional norms. In the spirit of Kant, therefore, I have pleaded for moral universalism and cosmopolitan federalism. I have not advocated open but rather porous borders; I have pleaded for firstadmittance rights for refugees and asylum seekers but have accepted the right of democracies to regulate the transition from first admission to full membership; I have also argued for subjecting laws governing naturalization to human rights norms and rejected the claim of a sovereign people not to permit naturalization and to bar the eventual citizenship of aliens in its midst.
} 
A soberania é especialmente apresentada como a capacidade do Estado de se autodeterminar. Em suma, a soberania do Estado não é teorizada como "poder", mas como "liberdade", para usar os termos de Jean Combacau. Enquanto os jurisconsultos da Lei das Gentes do século XVII ainda falavam em "poder soberano", os autores do século XVIII já falavam muito mais livremente em "nação soberana" ou "Estado livre e independente" (JOUANNET, 2014, p. 663, livremente traduzido). ${ }^{5}$

Nesse sentido, observa a necessidade de que se realoquem as práticas e princípios legais coloniais e imperialistas para seu momento histórico, correspondentes às duas grandes ondas de colonização europeia no mundo (séculos 15, 16 e 19), a fim de que se visualize que foram adotados inicialmente com intuito liberal e de segurança contra subordinações dentro da Europa. Somente num segundo momento passou a ser instrumento de exclusão. A partir disso, pretende que se reconheça que o Direito Internacional tem servido à dominação e à manutenção das distinções entre centro e periferia, reproduzindo as violações aos direitos humanos que ele próprio denuncia. Defende que a lei tanto pode ser instrumento de dominação como de paz e emancipação diante de políticas hegemônicas, a depender do contexto internacional, contexto cultural, econômico e político em que o Direito Internacional é aplicado concretamente (JOUANNET, 2014).

Não existe uma lei internacional "boa" ou uma lei internacional "ruim", mas um direito atravessado por tensões e contradições que pode ser tanto o instrumento das dominações mais brutais como um meio de solução para um mundo composto de sociedades plurais múltiplas e heterogêneas (JOUANNET, 2014, p. 671, em tradução livre). ${ }^{6}$

Pahuja também leciona acerca da possibilidade de o Direito Internacional ser apropriado, tanto para fins imperiais, quanto para a liberdade. Seus estudos referem-se à pós-colonialidade, pensamento que reflete o Oriente como construção simbólica do Ocidente, primeiras reflexões sobre a continuidade da exploração das ex-colônias. Para a professora, o Ocidente tem a constituição de sua identidade dependente da construção de um Outro, que possui as características que ele rejeita ou evidentemente carece. Trata-se de uma exclusão definidora. Por outro lado, pretende-se universal, o que significa incluir o que está excluído no seu próprio ato de constituição. Esse paradoxo explicaria o confronto entre liberdade e dominação no Direito Internacional (PAHUJA, 2005).

Este paradoxo - da autoconstituição circular do Outro e do eu, combinado com a aplicabilidade dessa afirmação - explica, pelo menos em parte, a dinâmica impulsionadora do Direito Internacional e sua intrigante contenção, tanto da promessa libertadora, quanto do perito imperialista. Além disso, explica por que estratégias baseadas na universalidade "genuína" ou na revalorização do Outro, ou mesmo projetos voltados para um desvelar político do Direito Internacional de maneira não específica, acabam por reproduzir o impulso imperialista (PAHUJA, 2005, p. 461, livremente traduzido). ${ }^{7}$

A autora delineia as dimensões da pós-colonialidade e suas implicações com referência a dois exemplos - universalização do Direito Internacional por meio da descolonização e o sucesso limitado das tentativas recentes de descolonizar os direitos humanos ao refundá-los em bases mais verdadeiramente universais. Afirma que, apesar de o Direito Internacional pretender estender-se a todos, há uma diferenciação entre o sujeito da lei e quem é abrangido mas não pode reivindicar a matéria dentro de si. Cita a Paz de Westfália, marco inicial

\footnotetext{
5 No texto original: La souveraineté est surtout présentée comme capacite de l'Etat-personne morale à se déterminer de façon indépendante. Bref, la souveraineté de l'Etat n'est pás théorisée comme une "puissance" mais comme une "liberte", pour reprende lês termes de Jean Combacau. Là où même les jurisconsultes Du droit des gens Du 170 siècle parlent encore de "puissance souveraine", lês auteurs du 18을 parlent beaucoup plus volontiers de "nation souveraine" ou d" Etat libre et indépendant".

6 No original: Il n'existe pas un "bon" droit international ni un "mauvais" droit international mais un droit traversé de tensions et de contradictions qui peut tout autant être l'instrument de la plus brutale des dominations qu'être une voie de solution pour um monde composé de multiples sociétés plurielles et hétérogènes entre elles.

7 Consta no original: This paradox - of the circular self-constitution of Other and self combined with the universal applicability of that claim - explains, at least in part, the impelling dynamic of international Law and its puzzling containment of both liberatory promise and imperializaing peril. Furthermore, it also explains why strategies that are based on producing "genuine" universality, or revalorizing the Other, or even projects taht are directed at the revelation of the politics of international Law in a non-specific way, are destined to reproduce the imperializing urge.
} 
do Direito Internacional para muitos estudiosos, como responsável por conceder o monopólio da personalidade jurídica às potências europeias e não como instrumento que estabeleceu a doutrina da soberania estatal, implicando um corte entre o eu e o outro (PAHUJA, 2005).

Daí a necessidade de as lutas coloniais serem pela libertação nacional e não pela descolonização (é indispensável a autodeterminação para a constituição como Estado-nação). A independência política, todavia, exigiu a criação de novas formas de dominação, e daí a criação das noções de "desenvolvimento" e "subdesenvolvimento", o que permitiu intervenções contínuas no Terceiro Mundo para a sua modernização. Manteve-se o outro, não mais como selvagem, mas como subdesenvolvido e o Direito Internacional, apesar de geralmente aplicável, deu continuidade à exploração.

No que se refere à descolonização dos direitos humanos, que, em sua origem tutela a liberdade do ser que é, e não do ser que não é, Pahuja (2005) afirma que diversas abordagens pós-coloniais tentaram avançar em sua direção. A sua suposta universalidade relaciona-se ao significado dado por euro-americanos. $O$ sujeito de direitos humanos é uma figura clássica, com premissa colonial, tornando evidente o locus de enunciação. Para a autora, não é mais possível negar a especificidade cultural do regime de direitos humanos e ignorar as origens coloniais do Direito Internacional. A professora afirma que se tem procurado revelar as fontes ocultas de valor positivo nos valores universais ostensivamente ocidentais, para que se reconheça a troca entre colonizados e colonizadores. Duvida, entretanto, que a refundação dos direitos humanos seja capaz de escapar à violência originária da criação do sujeito de direito: ao se procurar revalorizar culturas submetidas, pode-se conceder uma existência sólida ao outro.

Esta pós-colonialidade, em parte, descreve a maneira pela qual o Direito Internacional deve continuamente efetuar um corte entre o "eu" e o "Outro", tornando o que é excluído crucial para a formação do incluído, mas também reivindica a universalidade antitética para esta exclusão, cuja abrangência traz instabilidade produtiva para o coração do Direito Internacional (PAHUJA, 2005, p. 469, em livre tradução). ${ }^{8}$

Na América Latina os estudos acerca da subalternização dos saberes e práticas político-jurídicas deram-se sob a ótica da decolonialidade. Enquanto a teoria pós-colonial tem suas bases em Foucault, Derrida e Lacan, estando engajada com a experiência da colonização britânica ocorrida na Ásia, pelo que, em que pese a didática de Pahuja, os principais expoentes são Spivak, Guha e Bhabha, o pensamento decolonial pretende uma ruptura mais radical, uma desobediência epistêmica, em relação ao saber canônico europeu, sendo formado por pensadores latino-americanos ou comprometidos com a realidade latino-americana. A pretensão é de descolonizar o pensamento, pelo que parte do desvelar da colonialidade encoberta pela modernidade (BRAGATO, 2014).

A ideia de desobediência epistêmica, proposta central do pensamento descolonial, tem a ver com a necessidade de descolonizar o conhecimento. Essa conclusão decorre da constatação de que existe uma face oculta e encoberta da modernidade: a colonialidade. Colonialidade é um conceito cunhado por Anibal Quijano a partir das reflexões da teoria da dependência que lhe permitiram observar que as relações de dependência entre centro e periferia não se limitavam apenas ao âmbito econômico e político, mas se reproduziam também na construção do conhecimento. Com isso, o próprio conhecimento é passível de ser instrumento de colonização. A colonialidade é uma característica do poder exercido nas relações de dominação colonial da modernidade e nisso se diferencia do colonialismo em si, que é um processo de poder. A colonialidade é uma característica que provém deste processo e que ainda permanece sob diversas formas de neocolonialismo global ou colonialismos internos. Conforme esclarece Mignolo, a prática epistêmica descolonial surgiu "naturalmente" como consequência da formação destas estruturas de dominação, a que Aníbal Quijano chama de matriz colonial de poder e, por isso, tem como razão de ser e objetivo a descolonialidade do poder (BRAGATO, 2014, p. 211-212).

Lorca, nesse sentido, propõe uma releitura do Direito Internacional na América Latina, tido de origem ocidental, como reflexo da dogmática legal internacional dominante. Afirma que majoritariamente se assumiu o Direito Internacional como um fenômeno de origem europeia, que se estendeu concomitantemente com a

\footnotetext{
No original: This postcoloniality, in part, describes the way in which international Law must continually effect a cut between "self" and "Other", rendering that which is excluded crucial to the formation of the included, but it also makes a claim to universality antithetical to this exclusion and which in its encompassing brings this productive instability to the heart of international Law.
} 
expansão da Europa no mundo, com a América Latina sendo mera receptora ou, no máximo, contribuinte, das suas categorias jurídicas. Também, que pouco os próprios juristas latino-americanos consideram a existência de um modo latino-americano de pensar o Direito Internacional, diferentemente do que aconteceu no período de 1880 a 1950 . Há, entretanto, uma tradição regional do Direito Internacional na América Latina que não se relaciona simplesmente com as particularidades do local, mas diz respeito aos modos sustentados e padronizados nos quais os latino-americanos discordaram sobre estratégias de apropriação legal internacional (LORCA, 2006).

O projeto do século XIX de consolidar a independência dos novos Estados latino-americanos tinham a lei e a escola jurídica no seu centro, pois o esforço não era somente estabelecer as instituições certas para os jovens países independentes, mas também simbolizava aliar-se de forma ampla com os ideais liberais de progresso e civilizatórios gerados pelo movimento de independência. O Direito Internacional provou ser crítico em fornecer aos políticos latino-americanos um discurso que reforçasse a reivindicação de soberania para as novas nações, e a conquista de autonomia legal internacional emergiu como uma referência civilizacional valorizada. O estudo inovador de Liliana Obregon sobre a latino-americana escola jurídica internacional do século XIX mostra como os primeiros advogados internacionalistas compartilhavam uma crioula consciência legal (LORCA, 2006, p. 300, em livre tradução). ${ }^{9}$

Os estudos de Lorca bem revelam que de uma colonialidade do ser (outro excluído), que adveio da dominação inicialmente política, avançou-se para uma colonialidade do saber, em que se deu a subalternização do saber de um em razão do saber do outro, e, para mais além, houve a deslegitimação desses conhecimentos, numa colonialidade que pode ser denominada epistêmica (LORCA, 2006). É nesse sentido que Dussel afirma de maneira bastante radical que a construção discursiva iluminista culminou no desaparecimento da América Latina do mapa e da História, descartando-se os saberes nela produzidos e excluindo-a do centro geopolítico atual. O pensamento científico segue estritamente o modelo de racionalidade eurocêntrico, acentuando a dominação (DUSSEL, 2009).

Com efeito, a maneira mais directa de fundamentar a práxis de dominação colonial trans-oceânica - colonialidade que é simultânea à própria origem da modernidade e, por isso, novidade na história mundial - é mostrar que a cultura dominante outorga à mais atrasada ("torpeza" que Ginés chamará de turditatem, em latim, e Kant de unmündigkeit) os benefícios da civilização (DUSSEL, 2009, p. 295-296).

Sousa Santos trata do tema a partir da assimetria de saberes, que denomina diferença epistemológica e ocorre sobreposta à assimetria dos poderes. Afirma que há dois tipos ideais que acionam essa assimetria: o fascismo epistemológico, em que há uma relação violenta de destruição ou supressão de outros saberes, ocultando a epistemologia da força, e seu oposto, a ecologia dos saberes, que tenta minimizar ao máximo a assimetria, dando-se conta da imprescindibilidade da comparação com outros saberes para dar conta da complexidade. Leciona que o primeiro tipo tem predominado nas epistemologias hegemônicas da modernidade ocidental e nos modos de racionalidade e de pensamento que elas sustentam. Especificamente sobre a colonialidade, afirma Sousa Santos $(2009$, p. 468) que "o fascismo epistemológico existe sob a forma de epistemicídio, cuja versão mais violenta foi a conversão forçada e a supressão dos conhecimentos não ocidentais levadas a cabo pelo colonialismo europeu e que continuam hoje sob formas nem sempre mais subtis".

Desvelado o impacto que a lógica colonial tem na produção do conhecimento e, nesse sentido, na construção do Direito Internacional, o que se reflete na liberdade e na igualdade das populações das ex-colônias, ou seja, nas questões afetas às injustiças globais, passa-se à análise das repercussões no comércio de decisões, a fim de que se possa vislumbrar as possibilidades decoloniais na comunicação dos juízes para além das fronteiras políticas, de forma a promover justiça globalmente.

\footnotetext{
9 No texto original: The nineteenth-century project of consolidating independence in the new Latin American states had law and legal scholarship at its center, for the endeavor not only involved establishing the right institutions for the young independent nations, but also symbolized broader allegiances with the liberal ideals of progress and civilization generated by the independence movement. International law proved critical in providing Latin American politicians with a discourse to bolster the claim of sovereign autonomy for the new nations, and the attainment of international legal autonomy emerged as a prized benchmark for civilization. Liliana Obregon's ground-breaking study of nineteenth century Latin American international legal scholarship shows how early international lawyers shared a Criollo legal consciousness.
} 


\section{4 (PÓS)(DE)COLONIALIDADE E O COMÉRCIO ENTRE JUÍZES TRANSFRONTEIRIÇOS}

Allard e Garapon (2005), na obra Os juízes na mundialização, expõem o incremento da mobilidade do Direito, especialmente no que se refere à busca de sua efetividade. Atribuem aos juízes a engenharia dessa transformação, uma vez que eles já não estão mais adstritos a uma interpretação rigorosa do Direito e confinados ao território nacional, mas estabelecem, entre eles e para além das fronteiras, relações cada vez mais sólidas e confiantes. Para caracterizar as operações optaram por utilizar a expressão comércio entre juízes, ao invés de outras já usadas pela literatura especializada, como diálogo entre juízes e auditório global.

A expressão apresenta o mérito de remeter para as duas facetas da mundialização do direito: é simultaneamente uma rede de trocas, intercâmbios e uma forma de sociabilidade nascida do desejo de estabelecer redes sólidas, corteses e serenas, uma "dependência recíproca dos homens" (ALLARD; GARAPON, 2005, p. 9).

Allard e Garapon (2005) defendem que o comércio entre juízes não tem o intuito de formular uma ordem pós-nacional; ele apenas existe, sem apagar as relações de força entre os Estados ou deixar de ser incompleto. Trata-se de um fórum informal de intercâmbios situado, quase sempre, à margem dos mecanismos institucionais, sem caráter vinculante, mobilizados pelo sentimento ou consciência crescente de um patrimônio democrático ou civilizacional comum. Para esses autores (2005, p. 32), "em lugar de falarmos de um sistema judicial globalizado, que pressuporia uma organização hierárquica e um conjunto de normas comuns que não existem, poderíamos antes falar de uma 'sociedade de tribunais'".

A mundialização da justiça funciona, por conseguinte, como um princípio de estabelecimento de relações no termo do qual nenhum tribunal poderá permanecer indiferente aos seus homólogos, sem que, para tal, intervenham quaisquer vínculos ou instâncias físicas de coordenação, normalmente considerados como critérios de juridicidade. As relações assim induzidas não têm nada que ver com um sistema: não é necessário organizar ou ordenar estas ligações, que, nesse caso, perderiam indubitavelmente muito da sua força e flexibilidade inerentes. Não se espera que os juízes e os tribunais sejam, como se verifica num sistema, os agentes passivos de uma ordem jurídica, mas sim, pelo contrário, os intervenientes activos num comércio em constante evolução (ALLARD; GARAPON, 2005, p. 35-36).

O contexto é fértil aos estudos acerca da colonialidade, seja no que se refere ao conteúdo das trocas, considerando que seu propulsor é a verificação de um mesmo patrimônio democrático (colonialidade do ser e do saber), seja no que se refere às possibilidades de uma hierarquização velada e consequente subjugação dos saberes dos juízes do sul global (colonialidade epistêmica). Cabe questionar se a mundialização da Justiça será mais um processo de subalternização dos saberes e práticas político-jurídicas ou, considerando que se passa ao largo da institucionalização, se será fator de emancipação das populações colonizadas, dando azo à diversidade.

Shiva (2003) trata dos riscos de desaparecimento do saber local a partir da interação com o saber ocidental dominante, nos moldes das denúncias acerca da colonialidade. Cita a suposta universalidade dos sistemas ocidentais do saber, atentando para o fato de que o sistema dominante é também um sistema local, que tem base em determinada cultura, classe e gênero. Afirma que há um desvirtuamento da dicotomia universal/ local quanto às tradições do saber ocidental porque elas se propagaram pelo mundo inteiro por meio da colonização intelectual.

A ligação entre saber e poder é inerente ao sistema dominante porque, enquanto quadro de referência conceitual, está associado a uma série de valores baseado no poder que surgiu com a ascensão do capitalismo comercial. A forma pela qual esse saber é gerado, estruturado e legitimado e a forma pela qual transforma a natureza e a sociedade geram desigualdades e dominação, e as alternativas são privadas de legitimidade. 0 poder também é introduzido na perspectiva que vê o sistema dominante não como uma tradição local globalizada, mas como uma tradição universal, inerentemente superior aos sistemas locais (SHIVA, 2003, p. 22).

Nesse sentido, é de fácil percepção que o fluxo de conteúdo das decisões do norte em relação ao sul global tende a ser insuperavelmente superior, dado todo o discurso de que a racionalidade europeia traduz os anseios universais, promovendo os direitos humanos. Tanto é assim que, para não dizer inexistentes, escassos são os saberes jurídicos com origem nas ex-colônias que são utilizados na fundamentação de decisões proferidas dos países centrais. No Brasil, por exemplo, a reprodução acrítica de teorias alienígenas nas decisões ju- 
diciais é constantemente denunciada, uma vez que dissociada do contexto interno, desprezando a facticidade local, revelando-se verdadeira hierarquização não explícita do conhecimento. Na pré-compreensão do intérprete, fazem-se presentes a fenomenologia do sul e os textos jurídicos do norte global, ensejando dificuldades à compreensão e jurisprudência variante.

O incremento das trocas de decisões além-fronteiras, entretanto, poderá possibilitar que, à vista da maior incidência de determinados temas na periferia como, exemplificativamente, biopirataria, renda mínima, quebra de patentes de medicamentos, a sua discussão desenvolva-se com tamanha profundidade e detalhamento que inverta a lógica colonial. A larga experimentação das ex-colônias em determinadas temáticas processuais poderá ser fator de relevo para influenciar, considerada a informalidade da troca, a argumentação das sentenças dos juízes nos países centrais, para quem a questão quiçá seja inédita.

Trata-se de uma manifestação sofisticada do próprio conceito de integridade jurídica. A apropriação de uma integridade jurídica construída sob pilares transnacionais, os quais atuam em direção à capacidade de impulsionar decisões permeadas de responsabilidade social e política além-fronteiras, tendo como condição de possibilidade um sistema legal supra- articulado pelos direitos humanos e seu protagonismo antidiscricionário.

É dessa forma também que a intensificação das trocas entre os juízes servirá à interculturalidade e à consequente construção sincera do conhecimento global, enriquecido pela diversidade dos saberes locais, compreendidos num primeiro momento pelos juízes do próprio lugar e a partir deles compartilhados com os colegas de outros países. Isso fomentará a instituição de uma integridade jurídica em que o Direito simplesmente acabará por rejeitar o problema dos juízes em descobrirem-no ou inventarem-no, porquanto seu fundamento será fulcrado na fidelidade à história política da comunidade internacional.

No cenário da sociedade em rede, em que as transformações de tempo e espaço decorrentes do uso de novas tecnologias deram ensejo a que estranhos fossem obrigados a levar sua vida na companhia uns dos outros $^{10}$ e que a convivência cultural é elevada à condição da paz, ${ }^{11}$ o contrafluxo sul-norte propiciará sentenças judiciais nos países centrais com percepção mais adequada das diferentes identidades potencialmente envolvidas no litígio, aumentando as chances de pacificação social que se pretende alcançar nos processos judiciais e exponenciando a facticidade inserida na pré-compreensão dos julgadores.

\section{CONCLUSÃO}

As condições de possibilidade de o comércio transfronteiriço entre juízes ser fator de inversão da lógica colonial, promovendo justiça globalmente, portanto, passam pelo incremento das trocas de decisões jurídicas transfronteiriças a partir do sul global, dada a incidência reiterada de algumas temáticas nestes quiçá inéditas nos países centrais, a profundidade e o detalhamento que conste das argumentações presentes nas sentenças nas ex-colônias, capazes de influenciar os juízes dos países do norte, e, também, consideradas as transformações ocorridas na sociedade em rede, a diversidade dos saberes locais emerge como elemento indispensável ao enriquecimento dos julgamentos, dado que sobreleva a convivência cultural como condição da paz.

Desde Rawls, liberdade e igualdade convivem para a construção da Justiça, sendo a primeira o valor supremo da vida humana e, a segunda, reflexo do reconhecimento de que a sua limitação por meio das instituições, responsáveis pela distribuição dos bens, é o instrumento de sua maximização, o que alcança o âmbito das relações internacionais. Sen faz crítica construtiva a Rawls ao estabelecer outros bens primários, pretendendo uma concepção de Justiça possível, atento à promoção das liberdades reais, e vai além da atuação institucional, afirmando que há questões de Justiça global que independem da atuação dos Estados. $O$ ato justo é o que promove capacidades para que as pessoas façam escolhas.

\footnotetext{
${ }^{10}$ Ensina Bauman (2004, p. 138): "Como os estranhos são obrigados a levar suas vidas na companhia uns dos outros, independentemente das futuras guinadas da história urbana, a arte de viver em paz e feliz com a diferença, assim como de se beneficiar, serenamente, da variedade de estímulos e oportunidades, adquire enorme importância entre as habilidades que o morador da cidade deve adquirir e utilizar".

${ }^{11}$ Nesse sentido, explica Sen (2015, p. 33): "A grande esperança de harmonia em nosso mundo conturbado reside na pluralidade de nossas identidades, que se inter-relacionam e atuam contra divisões nítidas em torno de uma única linha enrijecida de uma veemente divisão a que pretensamente não se pode resistir".
} 
A partir de tais construções teóricas é que a filosofia política contemporânea desenvolve seus estudos acerca das injustiças globais, relacionadas num primeiro momento somente com as desigualdades socioeconômicas, mas já percebidas também como opressão da diversidade cultural e de identidade e subalternização dos saberes e práticas político-jurídicas. Pogge eleva os estudos de Rawls a uma análise institucional inicialmente global para a interna, preocupando-se com a injustiça socioeconômica, focando na interdependência global como fator de alocação de poder, à custa da periferia. Também a pobreza foi pauta nos esforços pós-Segunda Guerra, mas as políticas adotadas no ensejo do modelo desenvolvimentista revelaram-se uma continuidade da dominação colonial, o que foi acentuado pelo neoliberalismo. As tentativas de superação vêm com a construção de um novo Direito do Desenvolvimento, mais complexo e diversificado, com perspectiva não apenas econométrica, formulado como desenvolvimento sustentável, desenvolvimento humano e desenvolvimento social.

A opressão da identidade e da diversidade cultural é a injustiça combatida pelo Direito do Reconhecimento, para o qual há vida para além do valor biológico e da padronização eurocêntrica, não sendo tolerável a mazela de grupos estigmatizados e impondo-se a reparação de erros históricos. $O$ pertencimento não se refere apenas à cidadania, fazendo-se necessário um ajuste da legitimidade democrática, criando-se diferentes instâncias de participação política. A subalternização dos saberes e práticas político-jurídicas diz respeito à continuidade da lógica de inferiorização e dominação coloniais, que iniciaram em decorrência da dependência política e perpetuam-se nos discursos e no conhecimento.

Jouannet explica que o Direito das Gentes, apesar de ter sido inicialmente pensado para estabilizar as relações entre os países europeus, refutando hierarquias entre os Estados, acabou por legitimar o movimento colonial e de exclusão das populações periféricas. Defende que a lei que permite a dominação também pode ser instrumento de paz e emancipação diante de políticas hegemônicas. Pahuja, por sua vez, ensina a respeito dos estudos pós-coloniais, que reconhecem que a colonialidade iniciou do ser, como forma de estigmatizar o outro, aquele que pode ser usurpado ou explorado - o Oriente é uma construção simbólica do Ocidente, significando tudo que este rejeita ou evidentemente carece. Ressalta o paradoxo da pretensão ocidental de universalidade. Afirma que a independência política ensejou a criação de novas formas de dominação, daí a criação das noções de "desenvolvimento" e "subdesenvolvimento", e que os direitos humanos foram pensados para o ser que é, e não para o ser que não é. Trata da necessidade de se revelar as fontes ocultas de valor positivo nos valores universais ostensivamente ocidentais, explicitando as trocas entre colonizador e colonizado.

A decolonialidade é o viés latino-americano das teorias contra-hegemônicas, em que se propõe que houve um modo latino-americano de pensar o Direito Internacional. A colonialidade do ser é compreendida também do saber, uma vez que há o desprezo dos conhecimentos locais. O pensamento científico segue estritamente o modelo de racionalidade eurocêntrico e tudo mais não tem valor enquanto conhecimento, de forma a acentuar a dominação. Mais do que isso, a colonialidade passou a ser epistêmica, com a conversão forçada e supressão dos saberes não ocidentais, considerados atrasados e ilegítimos. Toda essa lógica colonial, portanto, impacta na construção dos saberes, inclusive nos jurídicos, e repercute no comércio de decisões.

Allard e Garapon utilizam a expressão comércio entre juízes para expor o aumento da mobilidade do Direito, por intermédio de redes informais e não hierarquizadas de intercâmbios entre os julgadores, que passaram a utilizar, como fundamentos, decisões já tomadas por colegas de outros países. O contexto é propício à colonialidade, visto que baseado na troca de saberes, e propulsionado pela ideia de que se tem um mesmo patrimônio democrático. Há preocupação com a construção dessa universalidade, a fim de que não tenha viés puramente eurocêntrico, considerando as ligações entre saber e poder. Afinal, muito mais frequente é o fluxo de conteúdo jurídico do norte para o sul global, inclusive bastante criticada no Brasil, por exemplo, a reprodução acrítica de teorias jurídicas alienígenas nas decisões.

Incentivar que os juízes transfronteiriços realizem o comércio de decisões como instrumento de emancipação das populações das ex-colônias e de convivência cultural pode ser compreendido como fator de (pós) (de)colonialidade, combatendo a subalternização dos saberes e práticas político-jurídicas e promovendo a justiça globalmente. Vislumbra-se essa possibilidade desde a profundidade e detalhamento de fundamentação de decisões proferidas pelos juízes do sul global em temas que lhe são mais recorrentes, como biopirataria, por exemplo, bem como considerando a diversidade dos saberes locais nos julgamentos, diante da aproximação dos diferentes pelas novas tecnologias e a indispensabilidade da convivência cultural à manutenção da paz. 


\section{REFERÊNCIAS}

ALLARD, Julie; GARAPON, Antoine. Os juízes na mundialização. A nova revolução do Direito. Lisboa: Instituto Piaget, 2005.

ANTONETTE, Amanda Krein; POZZATTI JUNIOR, Ademar. Da sociedade internacional justa à decente: fundamentos ético-morais de global justice para o tratamento de vítimas de violência de gênero no Brasil. In: NETO, Daniel Lena Marchiori; MOREIRA, Felipe Kern; FERREIRA, Luciano Vaz (org.). Estudos em Relações Internacionais, v. 1, p. 101-129. Rio Grande: Editora da Furg, 2018. Disponível em: https://ri.furg.br/images/Estudos-em-Rl---Volume-I.pdf. Acesso em: 26 jul. 2019.

BAUMAN, Zygmunt. Amor líquido: sobre a fragilidade dos laços humanos. Rio de Janeiro: Zahar, 2004.

BENHABIB, Seyla. The Rights of Others: Aliens, Residents and Citizens. New York: Cambridge University Press, 2004.

BRAGATO, Fernanda Frizzo. Para além do discurso eurocêntrico dos direitos humanos: contribuições da descolonialidade. Revista Novos Estudos Jurídicos, Eletrônica, v. 19, n. 1, jan./abr. 2014, p. 201-230. Disponível em: https://siaiap32.univali.br/seer/ index.php/nej/article/view/5548/2954. Acesso em: 29 jul. 2019.

CASTRO-GÓMEZ, Santiago. Ciências sociais, violência epistêmica e o problema da "invenção do outro". In: LANDER, Edgardo (org.). A colonialidade do saber: eurocentrismo e ciências sociais. Perspectivas latino-americanas. Títulos del Programa Sur-Sur, p. 80-87. Ciudad Autónoma de Buenos Aires, Argentina, set. 2005. Disponível em: https://edisciplinas.usp.br/pluginfile.php/2591382/mod_resource/content/1/colonialidade_do_saber_eurocentrismo_ciencias_sociais.pdf. Acesso em: 26 jul. 2019.

DUSSEL, Enrique. Meditações anti-cartesianas sobre a origem do anti-discurso filosófico da modernidade. In: SANTOS, Boaventura de Sousa; MENESES, Maria Paula (org.). Epistemologias do Sul. Coimbra: Edições Almedina, 2009. p. $283-335$.

HONNETH, Axel. Luta por reconhecimento: a gramática moral dos conflitos sociais. São Paulo: Ed. $34,2003$.

JOUANNET, Emmanuelle T. Des origines coloniales du Droit International: À propos du Droit des Gens Moderne au 18o siècle. In: AMICORUM, Líber; HAGGENMACHER, Peter. The Roots of International Law. Leiden: Martinus Nijhoff Publishers, 2014. p. 649-671.

JOUANNET, Emmanuelle. Le Droit International de La Reconnaissance. In: Revue Générale de Droit Inernational Public. Paris: Editions A. Pedone, 2012. p. 769-800.

JOUANNET, Emmanuelle T. O Direito Internacional. 2015. Disponível em: https://etourmejouannet.files.wordpress. com/2014/10/e-tourme-jouannet-o-direito-internacional.pdf. Acesso em: 29 jul. 2019.

LORCA, Arnulf. International Law in Latin America or Latin American International Law: Rise, Fall, and Retrieval of a Tradition of Legal Thinking and Political Imagination. Harvard International Law Jornal, Cambridge, v. 47, p. 283-305, dez. 2006.

MIGNOLO, Walter D. Colonialidade: o lado mais escuro da modernidade. Revista Brasileira de Ciências Sociais, v. 32, n. 94, p. 1-18, 2017. Disponível em: http://www.scielo.br/pdf/rbcsoc/v32n94/0102-6909-rbcsoc-3294022017.pdf. Acesso em: 26 jul. 2019.

PAHUJA, Sundhya. The Postcoloniality of International Law. Harvard International Law Journal, v. 46, p. 459-469, 2005.

POGGE, Thomas W. Para erradicar a pobreza sistêmica: em defesa de um dividendo dos recursos globais. SUR - Revista Internacional de Direitos Humanos, n. 6, ano 4, p. 142-166, 2007. Disponível em: http://www.scielo.br/pdf/sur/v4n6/a08v4n6.pdf. Acesso em: 11 dez. 2018.

RAWLS, John. Uma teoria da Justiça. São Paulo: Martins Fontes, 2000.

SANDEL, Michael J. Justiça: o que é fazer a coisa certa. Rio de Janeiro: Civilização Brasileira, 2015.

SANTOS, Boaventura de S. Um ocidente não-ocidentalista? A filosofia à venda, a douta ignorância e a aposta de Pascal. In: SANTOS, Boaventura de S.; MENEZES, Maria Paula (org.). Epistemologias do Sul. Coimbra: Edições Almedina, 2009. p. 445-486. SEN, Amartya. A ideia de justiça. São Paulo: Companhia das Letras, 2011.

SEN, Amartya. Identidade e violência: a ilusão do destino. São Paulo: Iluminuras: Itaú Cultural, 2015.

SHIVA, Vandana. Monoculturas da mente: perspectivas da biodiversidade e da biotecnologia. São Paulo: Editora Gaia, 2003. 